\title{
SOLUTION OF OPTIMAL POWER FLOW BASED ON COMBINED ACTIVE AND REACTIVE COST USING PARTICLE SWARM OPTIMIZATION
}

\author{
Harinder Pal Singh
}

Research Scholar, Department of Electrical Engg. IKG PTU Jalandhar, Punjab, India, Assistant professor, Department of Electrical Engg. SBSSTC, Ferozepur, Punjab, India

\section{Yadwinder Singh Brar}

Professor, IKG PTU Jalandhar, Punjab, India

\section{P. Kothari}

Director Research, Wainganga College of Engineering\& Management, Nagpur, Maharashtra, India

\begin{abstract}
ABTRACT
Thermal power generators have both active power $(A P)$ and reactive power (RP) requirement to meet up the total power demand. Considering the total power demand such generators supply the essential RP along with the AP. Consequently by considering the reactive power demand it is also an important to consider its cost along with the cost based on active power generation. In this paper, the generalised mathematical functions for the cost considering the RP are formulated and incorporated with the cost function based on active power generation. Particle Swarm Optimization (PSO) algorithm has been applied to solve Optimal power flow (OPF) problem (OPFP). The proposed work has been examined and tested on IEEE-9 bus system with different objectives such as total fuel cost based both active and reactive power generation, transmission losses, voltage profile improvement. The results drawn show its validity and effectiveness
\end{abstract}

Keywords: Economic Load dispach, Reactive power pricing, Optimal Power Flow, Particle Swarm Optimization.

Cite this Article: Harinder Pal Singh, Yadwinder Singh Brar and D. P. Kothari, Solution of Optimal Power Flow Based on Combined Active and Reactive Cost using Particle Swarm Optimization, International Journal of Electrical Engineering and Technology, 10(2), 2019, pp. 98-107.

http://iaeme.com/Home/issue/IJEET?Volume=10\&Issue=2 


\section{INTRODUCTION}

The main function of electric power system is to deliver electric energy to its loads efficiently at low cost. OPFP has been one of the most significant operational function and extensively studied subjects in the power system operation system and so it has acknowledged much consideration to the researchers in the past few decades. The main objective of OPF is to minimize the fuel cost (Economic Load Dispatch) and this can be done by assigning the optimal power generation of each unit to meet the total load demand [1]-[2]. Many approaches have been suggested to solve Economic Load dispatch (ELD) problem (ELDP) such as genetic algorithm (GA) [3], Hopfield neural Network(HNN) [4], particle swarm optimization (PSO) [5], evolutionary programming (EP) [6], biogeography based optimization (BBO) [7]. Under ELDP, the both active and reactive power is varied within min-max limits to meet the total demand and losses [1]. Reactive power is very essential for the secure operation of power systems. In power system network RP is required to meet total load demand therefore RP dispatch is equally important with real power dispatch. Mostly researchers have focused on cost considering AP and cost based on RP is not considered which may lead to false calculation of fuel cost. Therefore the cost considering reactive power has to be comprised in objective function of ELDP. In order to maintain the secure operation, a fair cost allocation method is required [8]-[9]. On the other hand, as the demand of electricity increasing continuously with unmatched generation and transmission capacity expansion, it leads to voltage instability and became a new challenge for power system planning and operation. Simultaneously, insufficient reactive power sources of power system produce large transmission loss. In such conditions, it may be essential to consider voltage stability margin and transmission loss as part of the objective of the OPF problem [10]. Different approaches have been suggested by researchers to solve OPF such as genetic algorithm[11], Particle swarm optimization [12], Differential Evolution(DE)[13], Simulating Annealing(SA)[14], Evolutionary Programming (EP) [15], biogeography based optimization (BBO) [16]. In this paper PSO algorithm has been applied to solve the OPF based on combine active and reactive power cost.

\section{PROBLEM FORMULATION}

\subsection{Problem Objectives}

The main objective of this problem is to minimise the total fuel cost corresponding to both AP and RP generation, voltage deviation and transmission losses with respect equality and in equality constraints. The details of objectives are given as below.

\subsubsection{Minimization of fuel cost considering AP generation.}

The fuel cost function considering AP generation by each thermal generator is given by a quadratic function can be written as [2]:

$$
F_{1}\left(P_{g i}\right)=\sum_{i=1}^{N G}\left(a_{i} P_{g i}^{2}+b_{i} P_{g i}+c_{i}\right) \$ / \mathrm{hr}
$$

where, $a_{i}, b_{i}$ and $c_{i}$ are the fuel cost coefficients of $\mathrm{i}^{\text {th }}$ unit, $P_{g i}$ is active power generation at $\mathrm{i}^{\text {th }}$ generator bus and NG is the number of generators.

\subsubsection{Minimization of fuel cost considering RP generation}

Cost considering reactive power is totally depends on AP output. When maximum power is produced by generators then RP generation is zero. Subsequently apparent power $\left(\mathrm{S}_{\mathrm{g}}\right)$ equals to $P_{\max }$. Moreover, generation of RP by generators reduces the production of AP. Therefore to produce RP $\left(Q_{g i}\right)$ operating at its nominal power $\left(P_{\max }\right)$, it is required to decrease its AP to $P_{g i}$ 
as shown in Fig.1 [8]. Therefore with the help of curve fitting, quadratic cost function of reactive power generation is formulated at the different values of $Q_{g i}$ correspond to $P_{g i}$. The fuel cost function of reactive power generation can be written as:

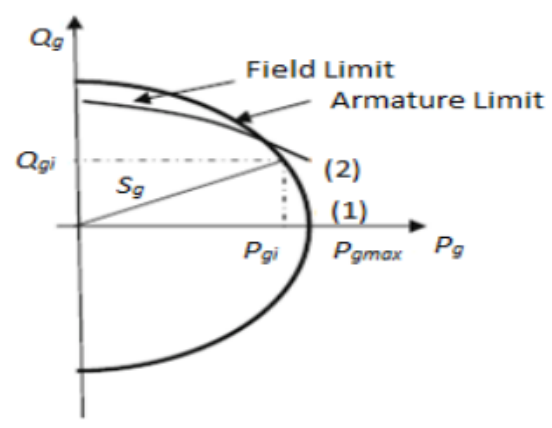

Figure 1 Capability curve of generator

$$
F_{2}\left(Q_{g i}\right)=\sum_{i=1}^{N G}\left(a_{q i} Q_{g i}^{2}+b_{q i} Q_{g i}+c_{q i}\right)
$$

where $a_{q i}, b_{q i}, c_{q i}$ are coefficients of reactive power and are shown in Table 2, $Q_{g i}$ is reactive power generation at $\mathrm{i}^{\text {th }}$ generator bus and number of generators are denoted by NG.

\subsubsection{Combined AP and RP Cost}

In order to get a precise cost value, the cost considering RP generation is to be considered with the cost of AP generation. The total cost is given by combining the cost considering AP generation as given in Eq.(1) and cost considering RP generation as given in Eq.(2). The objective function become as [8]:

$$
\text { Minimize } F_{3}=\sum_{i=1}^{N G} F_{1}\left(P_{g i}\right)+F_{2}\left(Q_{g i}\right)
$$

\subsubsection{Minimization of transmission Losses}

The losses in transmission lines are given by following equations

$$
\begin{gathered}
F_{4}=\sum_{i=i}^{N B} \sum_{\substack{j=1 \\
j \notin i}}^{N B}\left|Y_{i}\right| Y_{j}|| Y_{i j} \mid \cos \left(\theta_{i j}+\delta_{j}-\delta_{i}\right) \\
F_{5}=\sum_{i=i}^{N B} \sum_{\substack{j=1 \\
j \notin i}}^{N B}\left|V_{i}\right| V_{j}|| Y_{i j} \mid \sin \left(\theta_{i j}+\delta_{j}-\delta_{i}\right)
\end{gathered}
$$

Where $\left|V_{i}\right| \angle \delta_{i}$ : Voltage phasor in bus I, $Y_{i j} \angle \theta_{i j}: \mathrm{IJ}^{\text {th }}$ elements of admittance matrix

\subsubsection{Voltage Deviation}

The voltage profile is the most important index for system service quality. The improvement of the voltage profile contains reducing the deviation of load bus voltage from the unity. Considering the cost-based objectives in the OPF problem may result in a feasible solution that has unattractive voltage profile, so it is important to improve the voltage profile by minimizing the load bus voltage deviation from 1.0 per unit. The voltage deviation is represented by following function. 


$$
F_{6}=\sum_{i=1}^{N_{L}}\left|v_{i}-1\right|
$$

\subsection{Constraints}

\subsubsection{AP and RP balance constraints}

Total AP generation must meet the AP demand and the AP losses [28].

$$
\sum_{i=1}^{N G}\left(P_{g i}\right)-\left(\sum_{i=1}^{N B} P_{D i}+P_{L}\right)=0
$$

Total RP generation must meet the RP demand and the RP losses [28].

$$
\sum_{i=1}^{N G}\left(Q_{g i}\right)-\left(\sum_{i=1}^{N B} Q_{D i}+Q_{L}\right)=0
$$

where, $P_{D}, Q_{D}$ are the AP demand, RP demand

$P_{L}, Q_{L}$ are the AP losses, RP losses and are given as:

$$
\begin{gathered}
P_{L}=\sum_{i=i}^{N B} \sum_{\substack{j=1 \\
j \notin i}}^{N B}\left|V_{i}\right| V_{j} \| Y_{i j} \mid \cos \left(\theta_{i j}+\delta_{j}-\delta_{i}\right) \\
Q_{L}=\sum_{i=i}^{N B} \sum_{\substack{j=1 \\
j \notin i}}^{N B}\left|V_{i}\right| V_{j} \| Y_{i j} \mid \sin \left(\theta_{i j}+\delta_{j}-\delta_{i}\right)
\end{gathered}
$$

\subsubsection{Operating limits.}

The AP and RP generation by each unit must lie between minimum and maximum values.

$$
P_{g i}^{\min } \leq P_{g i} \leq P_{g i}^{\max } \quad(i=1,2, \ldots \ldots, N G)
$$

where, $P_{g i}^{\min }$ and $P_{g i}^{\max }$ are the minimum limit and maximum limit for AP generation.

$$
Q_{g i}^{\min } \leq Q_{g i} \leq Q_{g i}^{\max }(i=1,2, \ldots \ldots, N G)
$$

where, ${ }_{g i}^{\min }$ and $Q_{g i}^{\max }$ are the minimum limit and maximum limit for RP power generation. The voltage at each bus must be in the minimum limit and maximum limit

$$
\left|V_{i}^{\min }\right| \leq\left|V_{i}\right| \leq\left|V_{i}^{\max }\right|(i=1,2, \ldots \ldots, N B)
$$

\section{PARTICLE SWARM OPTIMIZATION(PSO)}

Let $X$ denotes a particle's position and $y$ denotes the particle's velocity respectively and both are initially calculated randomly. The ith particle position is denoted as $X_{i}=\left[X_{i 1}, Z_{i 2}\right.$, $\left.Z_{i 3}, \ldots \ldots \ldots, X_{i N G}\right]$ and the $i t h$ particle velocity is denoted as $y_{i}=\left[y_{i 1}, y_{i 2}, y_{i 3}, \ldots \ldots \ldots, y_{i N G}\right]$ in the number of particles (NP)-dimensional space. The previous best position (local best positions) of each particle is noted and denoted as $X_{i j}^{\text {best }}=\left[X_{i 1}^{\text {best }}, X_{i 2}^{\text {best }}, X_{i 3}^{\text {best }} \ldots \ldots \ldots . . . ., X_{i N G}^{\text {best }}\right]$. The best particle (Global best positions) among all the particles in the group is denoted by the $G_{j}^{\text {best }}=\left[G_{1}^{\text {best }}, G_{2}^{\text {best }}, G_{3}^{\text {best }} \ldots \ldots \ldots . . . ., G_{N G}^{\text {best }}\right]$. The new position and velocity of each particle can be solved by using the present position and the velocity values as given by [8]-[9]. 


$$
\begin{gathered}
y_{i j}^{\text {new }}=W \times y_{i j}+C_{1} \times R_{1} \times\left(X_{i j}^{\text {best }}-X_{i j}\right)+\left(C_{2} \times R_{2} \times\left(G_{j}^{b e s t}-X_{i j}\right)\right) \quad(i=1,2, . ., N P),(j=1,2, . ., N G) \\
X_{i j}^{n e w}=X_{i j}+y_{i j}^{\text {new }} \quad(i=1,2, . ., N P),(j=1,2, . ., N G)
\end{gathered}
$$

where, $N G$ is the number of members(generators) in a particle, $N P$ is the number of particles. $C_{1}$ and $C_{2}$ are the acceleration constants and are taken as $(2,2), W$ is the inertia weight factor is calculated using Eq. 16 as shown below, $X_{i j}^{\text {best }}$ is Local best positions, $G_{j}^{\text {best }}$ is Global best positions, $R_{l}$ and $R_{2}$ are constant random values in range[0,1]. $y_{i j}$ is the velocity of $j$ th member of $i$ th particle and it should be within the minimum and maximum limit $\left(y_{j}^{\min } \leq y_{j} \leq y_{j}^{\max }\right)$.

Inertia weight is given as:

$$
W=W^{\max }-\frac{W^{\max }-W^{\min }}{I T^{\max }} \times I T
$$

where, $I T^{\max }$ denotes the maximum value of iterations (generation) and $I T$ denotes the current iterations and $W^{\max }$ and $W^{\min }$ are taken as 0.9 and 0.4 .

\section{ALGORITHM FOR SOLUTION TECHNIQUE}

According to the discussion in above sections, the following procedure can be used for implementing the PSO algorithm.

- For each particle in the swarm $X_{i}$

○ Initialize the particle's position with a uniformly distributed random vector in the lower and upper boundaries of search-space.

- Apply Load flow and calculate the values of $\mathrm{P}_{\mathrm{L}}, \mathrm{Q}_{\mathrm{L}}$ and Voltage deviation.

- Evaluate the performance (fitness) of each particle based on objective function (case 1 to case 6)

- Find the minimum fitness out of each particle performance

- Assign the particle's best known position(local) to its initial position

- Assign the Global best position to the swarm's best known position(local) according to the minimum fitness value

- Initialize the particle's velocity within min-max boundaries of search-space

- Until a termination criterion is met (e.g. number of iterations performed), repeat

- For each particle

- Create a uniformly distributed random vectors $\mathrm{R}_{1}$ and $\mathrm{R}_{2}$

○ Update the particle's velocity: using Eq.14

- Update the particle's position by adding the velocity using Eq.15

- Apply load flow and calculate the values of $\mathrm{P}_{\mathrm{L}}, \mathrm{Q}_{\mathrm{L}}$ and Voltage deviation according to new positions.

- Evaluate the performance (fitness) according to new positions.

- IF the new fitness is less than the previous fitness THEN

- Update the new particle positions as the particle's best(local) known position

- Assign new fitness as the local fitness and find the minimum out of each.

- Update the swarm's best (global best) known position according to minimum fitness. 
Now best new positions hold the best found solution.

\section{RESULTS AND DISCUSSION}

This section represents the results obtained from the proposed algorithms. The problem was solved in PC with Intel i5, with 2.4GHz Processor and 4GB Ram. The proposed algorithm have been tested on IEEE 9 Bus system [8]. The system active and reactive demands are 3.15(pu) and $1.15(\mathrm{pu})$ respectively A swarm of 40 particles has been implemented on IEEE 9 Bus system (as shown in Figure 2). 6 different cases with different objective functions as explained below have been investigated. Table 1 shows the input data for active power cost calculation of IEEE 9 Bus system and Table 2 show the calculated cost coefficients for reactive power cost calculation of IEEE 9 Bus system. Table 3 shows the load characteristics. The results obtained are shown in Table 4.

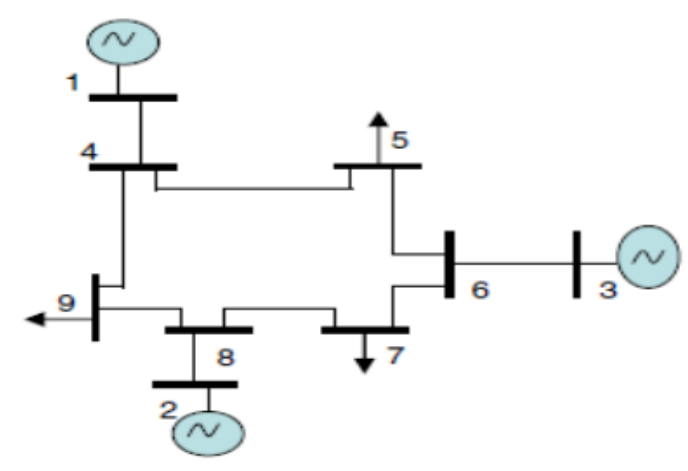

Figure 2: IEEE 9 Bus System.

Table 1 Generator Characteristics considering AP

\begin{tabular}{|c|c|c|c|c|c|c|c|}
\hline $\begin{array}{c}\text { No. Of } \\
\text { Buses }\end{array}$ & $\boldsymbol{a}_{\boldsymbol{P}}$ & $\boldsymbol{b}_{\boldsymbol{P}}$ & $\boldsymbol{C} \boldsymbol{p}$ & $\mathbf{P}_{\max }$ & $\mathbf{P}_{\min }$ & $\mathbf{Q}_{\max }$ & $\mathbf{Q}_{\min }$ \\
\hline 1 & 0.11 & 5 & 150 & 250 & 10 & 300 & -300 \\
\hline 2 & 0.08 & 1.2 & 600 & 600 & 10 & 300 & -300 \\
\hline 3 & 0.12 & 1 & 335 & 335 & 10 & 300 & -300 \\
\hline
\end{tabular}

Table 3 Derived fuel cost coefficients considering RP.

\begin{tabular}{|c|c|c|c|c|}
\hline$a_{2 i}^{2}$ & $a_{1 i}^{1}$ & $a_{0 i}^{0}$ & $Q_{\min }$ & $Q_{\max }$ \\
\hline 0.035 & 2.29 & -65.04 & -300 & 300 \\
\hline 0.025 & 1.55 & -48.44 & -300 & 300 \\
\hline 0.038 & 2.40 & -70.99 & -300 & 300 \\
\hline
\end{tabular}

Table 4 Load Characteristics.

\begin{tabular}{|c|c|c|}
\hline No. of Buses & Active Power (MW) & Reactive power (MVAR) \\
\hline 5 & 90 & 30 \\
\hline 7 & 100 & 35 \\
\hline 9 & 125 & 50 \\
\hline
\end{tabular}

\subsection{Case-1: Minimization of Total fuel cost considering both active and reactive power.}

In order to get an accurate cost function, it is important to consider the cost considering reactive power along with the cost considering active power. In this case total cost based on both active 
and reactive power is minimized. Losses are assumed to be zero. The objective function can be expresses as.

$$
f=\operatorname{Min}\left(F_{3}\right)+\text { penalty }
$$

Where $F_{3}$ is the total cost function as shown in Eq.(3).

$$
\text { Penalty }=K_{p}\left(\sum_{i=1}^{N G} P_{G i}-P_{D}\right)^{2}+K_{Q}\left(\sum_{i=1}^{N G} Q_{G i}-Q_{D}\right)^{2}
$$

Where $P_{G i}, Q_{G i}$ are the active, reactive power generation at $\mathrm{i}^{\text {th }}$ generator bus. $P_{D}, Q_{D}$ are the Total active power and total reactive power demand on generators.

$K_{P}, K_{q}$ are the penalty factors having large positive values set to 10,000 respectively.

Results obtained are shown in Table 4. It is seen from the results that the Total Fuel cost comes out to be $5283.319 \$ / \mathrm{hr}$.

\subsection{Case-2: Minimization of Total fuel cost considering both active and reactive power with OPF solution.}

In this case total cost considering both active and reactive power generation is minimized based on optimal power flow solutions.

$$
f=\operatorname{Min}\left(F_{3}\right)+\text { penalty }
$$

where, $F_{3}$ is the total cost function as shown in Eq. (3). Penalty $=K_{p}\left(P_{G_{S}}-P_{G_{S}}^{\lim }\right)^{2}+K_{Q}\left(Q_{G_{S}}-Q_{G_{S}}^{\lim }\right)^{2}$

$P_{G_{s}}, Q_{G_{s}}$ are the generations at slack bus are calculated using load flow. $P_{G_{S}}^{\lim }$ and $Q_{G_{S}}^{\lim }$ are the generation limit at slack bus. $K_{P}$ and $K_{Q}$ are the penalty factor having large positive value set to 10,000 .

As seen from the results (Table 4) that the total fuel cost comes out to be $5302.202 \$ / \mathrm{hr}$ and corresponding active, reactive power losses are 4.63348, -23.189 with voltage deviation of 0.27273 .

Cost in this case is increased by $0.35 \%$ than case 1 because of the presence of transmission losses. Slack generator has to supply the required amount of power so that total generation at generators is equal to sum of demand and losses

\begin{tabular}{|c|c|c|c|c|c|c|c|c|c|c|c|c|}
\hline \multirow[b]{2}{*}{$\begin{array}{l}\text { Gen. } \\
\text { No. }\end{array}$} & \multicolumn{2}{|c|}{ CASE 1} & \multicolumn{2}{|c|}{ CASE 2} & \multicolumn{2}{|c|}{ CASE 3} & \multicolumn{2}{|c|}{ CASE 4} & \multicolumn{2}{|c|}{ CASE 5} & \multicolumn{2}{|c|}{ CASE 6} \\
\hline & $\begin{array}{c}\mathbf{A P} \\
\left(\mathbf{P}_{\mathrm{gi}}\right) \mathbf{M} \\
\mathbf{W}\end{array}$ & $\begin{array}{c}\text { RP } \\
\left(Q_{g i}\right) M v \\
\text { ar } \\
\end{array}$ & $\begin{array}{c}\mathbf{A P} \\
\left(\mathbf{P}_{\mathrm{gi}}\right) \mathbf{M} \\
\mathbf{W} \\
\end{array}$ & $\begin{array}{c}\text { RP } \\
\left(\mathbf{Q}_{\text {gi }}\right) M \\
\text { var }\end{array}$ & $\begin{array}{c}\mathbf{A P} \\
\left(\mathbf{P}_{\mathrm{g})}\right) \mathbf{M} \\
\mathbf{W} \\
\end{array}$ & $\begin{array}{c}\text { RP } \\
\left(Q_{\text {gi }}\right) M \\
\text { var }\end{array}$ & $\begin{array}{c}\mathbf{A P} \\
\left(\mathbf{P}_{\mathrm{gi}}\right) \mathbf{M} \\
\mathbf{W}\end{array}$ & $\begin{array}{c}\text { RP } \\
\left(Q_{\text {gi }}\right) M \\
\text { var }\end{array}$ & $\begin{array}{c}\mathbf{A P} \\
\left(\mathbf{P}_{\mathrm{gi}}\right) \mathbf{M} \\
\mathbf{W}\end{array}$ & $\begin{array}{c}\text { RP } \\
\left(\mathbf{Q}_{\text {gi }}\right) M \\
\text { var }\end{array}$ & $\begin{array}{c}\mathbf{A P} \\
\left(\mathbf{P}_{\mathrm{gi}}\right) \mathbf{M} \\
\mathbf{W}\end{array}$ & $\begin{array}{c}\text { RP } \\
\left(\mathbf{Q}_{\text {gi }}\right) M \\
\text { var }\end{array}$ \\
\hline 1 & $\begin{array}{c}83.519 \\
200 \\
\end{array}$ & $\begin{array}{c}30.6054 \\
70\end{array}$ & $\begin{array}{c}89.51 \\
72 \\
\end{array}$ & $\begin{array}{c}16.815 \\
3 \\
\end{array}$ & $\begin{array}{c}178.4 \\
29 \\
\end{array}$ & $\begin{array}{c}91.540 \\
6 \\
\end{array}$ & $\begin{array}{c}159.1 \\
586 \\
\end{array}$ & $\begin{array}{c}96.320 \\
8 \\
\end{array}$ & $\begin{array}{c}96.75 \\
224 \\
\end{array}$ & $\begin{array}{c}39.616 \\
6 \\
\end{array}$ & $\begin{array}{c}157.0 \\
661 \\
\end{array}$ & $\begin{array}{c}58.621 \\
3 \\
\end{array}$ \\
\hline 2 & $\begin{array}{c}138.34 \\
160 \\
\end{array}$ & $\begin{array}{c}57.6875 \\
40 \\
\end{array}$ & $\begin{array}{c}136.2 \\
14 \\
\end{array}$ & $\begin{array}{c}50.403 \\
0 \\
\end{array}$ & $\begin{array}{c}59.81 \\
19 \\
\end{array}$ & $\begin{array}{c}2.6049 \\
7 \\
\end{array}$ & $\begin{array}{c}92.15 \\
456 \\
\end{array}$ & $\begin{array}{c}17.343 \\
9 \\
\end{array}$ & $\begin{array}{c}130.6 \\
807 \\
\end{array}$ & $\begin{array}{c}29.576 \\
6 \\
\end{array}$ & $\begin{array}{c}152.6 \\
076 \\
\end{array}$ & $\begin{array}{c}23.968 \\
7 \\
\end{array}$ \\
\hline 3 & $\begin{array}{c}93.139 \\
200\end{array}$ & $\begin{array}{c}26.7069 \\
90\end{array}$ & $\begin{array}{c}93.94 \\
09 \\
\end{array}$ & $\begin{array}{c}24.553 \\
4 \\
\end{array}$ & $\begin{array}{c}80.67 \\
30 \\
\end{array}$ & $\begin{array}{c}20.910 \\
2 \\
\end{array}$ & $\begin{array}{c}67.66 \\
285 \\
\end{array}$ & $\begin{array}{c}1.4098 \\
0 \\
\end{array}$ & $\begin{array}{c}92.02 \\
802 \\
\end{array}$ & $\begin{array}{c}27.533 \\
1 \\
\end{array}$ & $\begin{array}{c}10.00 \\
333 \\
\end{array}$ & $\begin{array}{c}32.415 \\
6 \\
\end{array}$ \\
\hline $\begin{array}{l}\text { Cost } \\
(\$ / h r)\end{array}$ & $\begin{array}{c}5101.1 \\
06 \\
\end{array}$ & $\begin{array}{c}182.213 \\
600\end{array}$ & $\begin{array}{c}5214 . \\
7 \\
\end{array}$ & $\begin{array}{c}87.407 \\
2 \\
\end{array}$ & $\begin{array}{c}6698 . \\
84 \\
\end{array}$ & $\begin{array}{c}389.45 \\
4 \\
\end{array}$ & $\begin{array}{c}6074 . \\
291 \\
\end{array}$ & $\begin{array}{c}398.68 \\
6 \\
\end{array}$ & $\begin{array}{c}5229 . \\
811 \\
\end{array}$ & $\begin{array}{c}123.78 \\
3 \\
\end{array}$ & $\begin{array}{c}6652 . \\
272 \\
\end{array}$ & $\begin{array}{c}239.29 \\
03 \\
\end{array}$ \\
\hline $\begin{array}{l}\text { Total } \\
\text { Cost } \\
\text { (\$/hr) }\end{array}$ & \multicolumn{2}{|c|}{5283.319000} & \multicolumn{2}{|c|}{5302.202000} & \multicolumn{2}{|c|}{7088.303000} & \multicolumn{2}{|c|}{6472.977000} & \multicolumn{2}{|c|}{$\mathbf{5 3 5 3 . 5 9 4 0 0 0}$} & \multicolumn{2}{|c|}{6891.563000} \\
\hline
\end{tabular}

Table 4 OPF results obtained for IEEE 9 bus system considering both Active and reactive power generation 


\begin{tabular}{|c|c|c|c|c|c|c|c|c|c|c|c|c|}
\hline \multirow[b]{2}{*}{$\begin{array}{l}\text { Gen. } \\
\text { No. }\end{array}$} & \multicolumn{2}{|c|}{ CASE 1} & \multicolumn{2}{|c|}{ CASE 2} & \multicolumn{2}{|c|}{ CASE 3} & \multicolumn{2}{|c|}{ CASE 4} & \multicolumn{2}{|c|}{ CASE 5} & \multicolumn{2}{|c|}{ CASE 6} \\
\hline & $\begin{array}{c}\mathbf{A P} \\
\left(\mathbf{P}_{\mathrm{g}}\right) \mathbf{M} \\
\mathbf{W}\end{array}$ & $\begin{array}{c}\mathbf{R P} \\
\left(\mathbf{Q}_{\mathrm{g}}\right) \mathbf{M v} \\
\mathbf{a r} \\
\end{array}$ & $\begin{array}{c}\mathbf{A P} \\
\left(\mathbf{P}_{\mathrm{gig}}\right) \mathbf{M} \\
\mathbf{W}\end{array}$ & $\begin{array}{c}\mathbf{R P} \\
\left(\mathbf{Q}_{\mathrm{gi}}\right) \mathbf{M} \\
\mathbf{v a r} \\
\end{array}$ & $\begin{array}{c}\mathbf{A P} \\
\left(\mathbf{P}_{\mathrm{g}}\right) \mathbf{M} \\
\mathbf{W}\end{array}$ & $\begin{array}{c}\mathbf{R P} \\
\left(\mathbf{Q}_{\mathrm{gi}}\right) \mathbf{M} \\
\mathbf{v a r} \\
\end{array}$ & $\begin{array}{c}\mathbf{A P} \\
\left(\mathbf{P}_{\mathbf{g i}}\right) \mathbf{M} \\
\mathbf{W} \\
\end{array}$ & $\begin{array}{c}\mathbf{R P} \\
\left(\mathbf{Q}_{\mathrm{gi}}\right) \mathbf{M} \\
\mathbf{v a r} \\
\end{array}$ & $\begin{array}{c}\mathbf{A P} \\
\left(\mathbf{P}_{\mathrm{gi}}\right) \mathbf{M} \\
\mathbf{W}\end{array}$ & $\begin{array}{c}\mathbf{R P} \\
\left(\mathbf{Q}_{\mathrm{gi}}\right) \mathbf{M} \\
\mathbf{v a r}\end{array}$ & $\begin{array}{c}\mathbf{A P} \\
\left(\mathbf{P}_{\mathrm{gi}}\right) \mathbf{M} \\
\mathbf{W} \\
\end{array}$ & $\begin{array}{c}\mathbf{R P} \\
\left(\mathbf{Q}_{\mathrm{gi}}\right) \mathbf{M} \\
\mathbf{v a r}\end{array}$ \\
\hline $\begin{array}{c}\text { Active } \\
\text { Loss }\end{array}$ & \multicolumn{2}{|c|}{-} & \multicolumn{2}{|c|}{4.63348} & \multicolumn{2}{|c|}{4.135689} & \multicolumn{2}{|c|}{4.24420} & \multicolumn{2}{|c|}{4.493943} & \multicolumn{2}{|c|}{4.7198} \\
\hline $\begin{array}{l}\text { Reacti } \\
\text { ve } \\
\text { Loss }\end{array}$ & & & \multicolumn{2}{|c|}{-23.189} & \multicolumn{2}{|c|}{$\mathbf{0}$} & \multicolumn{2}{|c|}{$\mathbf{0}$} & \multicolumn{2}{|c|}{-18.2769} & \multicolumn{2}{|c|}{$\mathbf{0}$} \\
\hline $\begin{array}{c}\sum \text { Volt } \\
\text { age } \\
\text { Deviat } \\
\text { ion } \\
\text { (PU) }\end{array}$ & \multicolumn{2}{|c|}{-} & \multicolumn{2}{|c|}{0.27273} & \multicolumn{2}{|c|}{0.64454} & \multicolumn{2}{|c|}{0.7248} & \multicolumn{2}{|c|}{0.1608842} & \multicolumn{2}{|c|}{0.28721} \\
\hline $\begin{array}{c}\text { Time } \\
\text { (secon } \\
\text { ds) }\end{array}$ & \multicolumn{2}{|c|}{11.40} & \multicolumn{2}{|c|}{13.87} & \multicolumn{2}{|c|}{31.37} & \multicolumn{2}{|c|}{36.24} & \multicolumn{2}{|c|}{37.06} & \multicolumn{2}{|c|}{37.36} \\
\hline
\end{tabular}

\subsection{Case3: Minimization of active and reactive transmission losses}

In this case both active and reactive power losses are minimized and the problem becomes multiobjective problem. The objective function can be expressed as:

$$
f=\lambda_{P_{L}}\left(F_{4}\right)+\lambda_{Q_{L}}\left(F_{5}\right)+\text { penalty }(\$ / h r)
$$

Where. $F_{4}$ and $F_{5}$ are the active and reactive transmission losses as shown in Eq.(4) and Eq.(5). $\lambda_{p_{L}}$ and $\lambda_{Q_{L}}$ are the weighting factor, which are selected 2,000 and 1500 respectively in this case.

$$
\text { Penalty }=K_{p}\left(P_{G_{s}}-P_{G_{s}}^{\lim }\right)^{2}+K_{Q}\left(Q_{G_{s}}-Q_{G_{s}}^{\lim }\right)^{2} . K_{P} \text { and } K_{Q} \text { are the penalty factor having }
$$

large positive value set to $1,000 . P_{G_{s}}$ and $Q_{G_{s}}$ are the generation at slack bus. $P_{G_{s}}^{\lim }, Q_{G_{s}}^{\lim }$ are the generation limit at slack bus. As seen from the results (Table 4), the active power losses reduced by $10.7 \%$ and Reactive power losses become almost zero with increase in fuel cost by $25.2 \%$ than case 2 .

\subsection{Case4: Minimization of Total fuel cost with transmission losses.}

In this case total fuel cost considering active and reactive power, active transmission losses and reactive transmission losses are minimizes simultaneously. The objective function can be expresses as.

$$
f=\left(F_{3}\right)+\lambda_{P_{L}}\left(F_{4}\right)+\lambda_{Q_{L}}\left(F_{5}\right)+\text { penalty }(\$ / h r)
$$

Where $F_{3}$ is the cost function as shown in Eq.(3), $F_{4}$ and $F_{5}$ are the active and reactive transmission losses as shown in Eq.(4) and Eq.(5). $\lambda_{p_{L}}$ and $\lambda_{Q_{L}}$ are the weighting factor, which are selected 2,000 and 1500 respectively in this case. Penalty $=K_{p}\left(P_{G_{S}}-P_{G_{s}}^{\lim }\right)^{2}+K_{Q}\left(Q_{G_{s}}-Q_{G_{s}}^{\lim }\right)^{2} \cdot P_{G_{s}}$ and $Q_{G_{s}}$ are the generation at slack bus. $P_{G_{S}}^{\lim }$ , $Q_{G_{S}}^{\lim }$ are the generation limit at slack bus. As seen from the results (Table 4), the active transmission losses are reduced by $8.4 \%$ and reactive transmission losses become zero and corresponding total fuel cost increased by $18.08 \%$ as compared to case 2 .

\subsection{Case5: Minimization of Total fuel cost with voltage deviation.}

In this case total fuel cost along with voltage deviation is minimized simultaneously. The objective function can be expressed as. 
Solution of Optimal Power Flow Based on Combined Active and Reactive Cost using Particle Swarm Optimization

$$
f=\left(F_{3}\right)+\lambda_{v d}\left(F_{6}\right)+\text { penalty }(\$ / h r)
$$

where, $F_{3}$ is the cost function as shown in Eq.(3), $\lambda_{v d}$ is the weighting factor value, which is selected 1000 in this case. Penalty $=K_{p}\left(P_{G_{s}}-P_{G_{s}}^{\lim }\right)^{2}+K_{Q}\left(Q_{G_{S}}-Q_{G_{s}}^{\lim }\right)^{2} \cdot P_{G_{s}}$ and $Q_{G_{s}}$ are the generation at slack bus. $P_{G_{s}}^{\lim }$ and $Q_{G_{s}}^{\lim }$ are the generation limit at slack bus. As seen from result (Table 4 ), the voltage deviation is reduced by $40 \%$ with increase in $0.9 \%$ of fuel cost as compared to case 2 .

\subsection{Case6: Minimization of Total fuel cost, voltage deviation and total transmission losses.}

In this case total fuel cost along with voltage deviation and both active and reactive transmission losses are minimized simultaneously. The objective function can be expressed as.'

$$
f=\left(F_{3}\right)+\lambda_{v d}\left(F_{6}\right)+\lambda_{P_{L}}\left(F_{4}\right)+\lambda_{Q_{L}}\left(F_{5}\right)+\text { penalty }(\$ / h r)
$$

Where $F_{3}$ is the cost function as shown in Eq. (3).

$\lambda_{v d}, \lambda_{p_{L}}$ and $\lambda_{Q_{L}}$ are the weighting factor, which are selected 3000,2000 and 1500 in this case. Penalty $=K_{p}\left(P_{G_{S}}-P_{G_{S}}^{\lim }\right)^{2}+K_{Q}\left(Q_{G_{S}}-Q_{G_{S}}^{\lim }\right)^{2} \cdot P_{G_{s}}$ and $Q_{G_{s}}$ are the generation at slack bus. $P_{G_{S}}^{\lim }, Q_{G_{S}}^{\lim }$ are the generation limit at slack bus. As seen from the results (Table 4), the total fuel cost is increased by $23.06 \%$, reactive transmission losses reduced to zero, Active transmission losses and voltage deviation becomes almost same as compared with case 2 .

\section{CONCLUSION}

In this paper different cases related to OPFP have been discussed. PSO algorithm is applied to solve such problems. In OPFP, main focus is on minimising the cost considering active power generation. Generators also need to supply RP along with the AP in to meet total power generation, so cost based on RP generation is need to be considered along with the cost based on AP generation otherwise it may results false calculation. Considering importance of reactive power cost, function-based cost based on RP generation is formulated. Developed algorithm based on PSO is tested on IEEE 9 bus system. Furthermore 6 cases related to minimization of fuel cost, voltage deviation and transmission loss has been solved. Obtained results show its effectiveness and robustness. In future the developed algorithm can be tested on large power network systems by incorporating the effect of tap changing transformers, shunt var compensators and varying the generator voltages etc.

\section{REFERENCES}

[1] Miller RH, Malinnowski JH, "Power System Operation”, McGraw-Hill, Inc.1994.

[2] Kothari DP, Dhillon JS, "Power System Optimization", Second Edition, PHI learning Private limited 2011.

[3] Walter DC, Sheble GB, "Genetic algorithm solution of economic dispatch with valve point loading”, IEEE Trans. Power Syst. 1993; 8(3): 1325-1332, August

[4] Ching-Tzong S., Chien-Tung L.,New approach with a Hopfield modeling framework to economic dispatch, IEEE Trans. Power Syst., 2000,15(2):541-545

[5] Immanuel Selvakumar A., Thanushkodi K., A New Particle Swarm Optimization Solution to Nonconvex Economic Dispatch Problems, IEEE Trans. Power Syst., 2007, 22(1): 42-5

[6] Sinha N, Chakrabarti R, Chattopadhyay PK, "Evolutionary programming techniques for economic load dispatch," IEEE Trans. Evol. Comput. 2003; 7(1): 83-94, February 
[7] Bhattacharya A., Chattopadhyay P.K., Biogeography Based optimization for different economic load dispatch problems, IEEE Trans. Power Syst., 2010,25(2):1064-1077.

[8] Hasanpour S, Ghaziand R, Javidi MH, "A new approach for cost allocation and reactive power pricing in a deregulated environment”, Electrical Engg.2009; 91(1): 27-34.

[9] Singh, H.P. Brar, Y.S. Kothari D.P, “Active and reactive power dispatch using predator prey optimization approach," Proceeding of IEEE 7th Indian international conference on Power electronics (IICPE 2016), Thapar university, Patiala, Punjab, India.(17-19) Nov.2016 . ISSN: 2160-3170, pp. 1-6

[10] Mandal, B. Roy, P.K. "Multi-objective optimal power flow using quasi-oppositional teaching learning-based optimization", Applied soft computing, 2014, 21, 590-606.

[11] Lai L.L, Ma JT. "improved genetic algorithm for optimal power flow under both normal and contingent operation states", Int. J Elec. Pwr. Energy Syst. 1997; 19(5), 287-292.

[12] Abido MA. Optimal power flow using particle swarm optimization. Electr Power Energy Syst 2002; 24: 563-71.

[13] Varadarajan M, Swarup KS. Solving multi-objective optimal power flow using differential evolution. IET Gener Transm Distrib 2008; 2(5):720-30.

[14] Roa-Sepulveda CA, Pavez-Lazo BJ. A solution to the optimal power flow using simulated annealing. Electr Power Energy Syst 2003;25:47-57.

[15] Somasundaram P, Kuppusamy K, Kumudini Devi RP. Evolutionary programming based security constrained optimal power flow. Electr Power Syst Res 2004;72:137-145

[16] Bhattacharya A, Chattopadhyay PK. "Application of biogeography-based optimization to solve different optimal power flow problems". IET Gener. Transm. Distrib. 2011;5 (1):7080.

[17] Layth Abdulrasool Mahdi, Mohammed Abbas Al-Jumaili, Analytical Solution of Stresses Developed by High Pressure Aircraft. International Journal of Civil Engineering and Technology, 9(7), 2018, pp. 1685-1695. 